\title{
A Study of Current Situation of Negotiated Teaching in Chinese Foreign Language Classroom
}

\author{
Li-hua Tang \\ College of Foreign Language Education of China \\ West Normal University, \\ Nanchong, Sichuan, China \\ 16867933@qq.com
}

\begin{abstract}
Negotiated teaching is the adjustment between teachers and students in foreign language learning, so as to ensure the progress of classroom interaction, and ultimately achieve the purpose of promoting the development of students language ability. In this study, the literature research method was used to comb and analyze the relevant domestic literature. Through theoretical discussion, the theoretical and practical problems of foreign language consultation teaching in China are systematically and deeply explored.
\end{abstract}

Keywords-negotiated teaching; autonomous learning; cooperative awareness

\section{INTRODUCTION}

Negotiated teaching is the adjustment between teachers and students in foreign language learning, so as to ensure the progress of classroom interaction, and ultimately achieve the purpose of promoting the development of students' language ability[1]. As a special form of classroom interaction, negotiated teaching is to help students understand the language input and increase language output. It encourages students to improve foreign language accuracy and fluency, so as to enhance the teaching quality. In the current foreign language classroom, there is a universal problem of unidirectional control of teachers and lack of communication and interaction between teachers and students. Such problems not only make classroom teaching dull, but also arouse the initiative of teachers and students in classroom teaching, which seriously violates the rule of language teaching, which is not conducive to cultivate students' ability of using foreign languages. Foreign language negotiated teaching is of both theoretical and practical significance, and it is also the need to improve the realistic foreign language classroom teaching[2].

\section{The Current States and Progress of the Study on THE Negotiated Teaching in Foreign LANGUAGE CLASSROOM}

Negotiated teaching is in a category of classroom interaction, which has been widely popular in foreign countries in 1980s, but it has just started in China. It can be said that the research in this area has been dominated by western scholars[3]. In recent years, especially since 2000, with the popularization of learner centered communicative approach and task-based teaching method in China, the deliberative interactive research is rising to become one of the hot topics in the country[4]. Research articles and dissertations on foreign language negotiation have also begun to appear, but the number is very small. It is usually an introduction to relevant foreign theories and research results, or a survey on a certain aspect of the consultation between teachers and students on the basis of the Chinese foreign language classroom environment. The research is in the journal articles and dissertations after 2000.

\section{A. Research on Negotiated Teaching in Foreign Language Classroom in China}

\section{1) Journal articles}

Through the major foreign language periodicals in China since 2000, 9 articles about the Negotiated Teaching in the foreign language classroom have been collected, which mainly involve the following two aspects.

From the perspective of foreign language teacher's classroom strategy research, Yang Xueyan summarized the research situation of negotiated teaching in the West and introduced the main research achievements in Western foreign language classroom[5]. From the perspective of second language acquisition in the classroom, Liu Xuehui introduced and analyzed the concept of negotiated teaching in two language classes. With the input hypothesis and the interactive hypothesis as the theoretical framework, this paper introduces the characteristics of negotiated teaching and Its Enlightenment to college English classroom teaching. Based on the interaction hypothesis of Long and the output hypothesis of Swain, Zhou Junping expounded the role of negotiated teaching in learner language development and its practical significance to college English classroom teaching in China. With the process of foreign language learning psychology consultation teaching as the theoretical basis, Ma Dongmei deeply analyzes the main factors affecting the process of communication between background knowledge and communicative relationship, communication strategies, task type, self-confidence, personality and learning motivation. Fang Wenli discussed the relationship between negotiated teaching and the training of students' communicative competence and the role they played[6].

Referring to BOULIMA's foreign language classroom interaction analysis system, Liu Xuehui divides the consultations into three categories, namely, meaning negotiation, formal negotiation and content consultation. Zhou 
Xingzhou conducted a case study on the phenomenon of negotiated teaching, and pointed out that all kinds of negotiated teaching methods used by the surveyed teachers can generally increase student output opportunities, but not all of them can effectively improve the quantity and quality of student output. From the results of the study, it can be seen that when teachers are studying negotiated teaching, the confirmation and verification are more used. Zheng Peiyun explored the potential advantages and constraints of negotiated teaching from many angles. She points out that negotiated teaching has the advantages of stimulating self-correction, but at the same time it is restricted by factors such as time, content and way of negotiation.

\section{B. Degree Thesis}

By searching for CNKI academic journals, Chinese Doctoral Dissertations Full-text Database, National Library and other resources, we searched 8 papers on foreign language negotiation teaching.

Based on interaction theory, Zhao Guoxia describes the interaction between teachers and students in two aspects: Teacher Questioning and student response, teacher feedback and student follow-up. The purpose of this study is to understand whether the process of consultation between teachers and students can provide the necessary environment to meet the learners' development of language, cognition and emotional needs[7]. Thus help them to construct knowledge actively and promote foreign language learning. At the same time, this paper discusses the influence of this interactive environment on the use of learners' interlanguage. The results show that the negotiated teaching in the College English classroom is relatively single in form and the number is obviously insufficient. Teachers play a leading role in the process of negotiation and interaction between teachers and students, and the students are still passive and conservative. Students' participation in consciousness and participation needs to be improved. This paper is the earliest degree thesis involving negotiated teaching, and it is the first attempt to explain the meaning negotiation, form negotiation and content negotiation in foreign language classroom. However, the consultation is only part of the full text, and the research on the process of negotiation between teachers and students is not enough, comprehensive and systematic. Qian Weiwei studied the negotiated teaching in middle school, and counted the percentage of consultative interaction between teachers and students and the percentage of non-sense negotiation interaction in the classroom. The article distinguishes three types of negotiation behavior, such as meaning, form and content. The number of the three consultations was examined. The teachers studied the influence of the number of students' consultation and the different types of negotiation behavior on the classroom teaching activities.

Zhao Xiaomei used Boulima's classroom discourse analysis system as a classification standard, studied and counted the strategies of promoting students' output in the process of consultation. She also analyzed the different reactions of students to these means. Research shows that the classroom interaction between teachers and students are not the type of negotiation of meaning, interactive meaning negotiation rarely. It was most initiated by teachers, and students only had the passive participation. The frequency of teachers' use of three types of negotiation is meaning negotiation, content negotiation and formal negotiation in turn. From the results of research, negotiated teaching in the middle school English classroom role is mainly about the adjustment, overcoming obstacles, the discourse understanding, creating opportunities, increasing students' language output and improve their ability of using language. Based on the theory of interaction, Shao Dangxi explored the influence of teacherstudent negotiation interaction on students' language output based on the theory of interaction. It mainly investigated the distribution of three kinds of negotiation in university classroom environment, such as meaning negotiation, form negotiation and content negotiation. At the same time, he analyzed the influence of three kinds of negotiation on students' output respectively, so as to analyze the value and significance of negotiated interaction for students' language acquisition.

\section{The Problems in the Study of Negotiated Teaching IN CHINA}

The research on foreign language negotiated teaching abroad is much earlier and much richer from the aspect of research content. The depth and breadth of research are deeper and wider. It can be said that the research in this area is dominated by western scholars.

In recent years, Chinese researchers began to pay attention to the topic of foreign language negotiated teaching. They introduced the Western related theoretical assumptions and concepts, and investigated the negotiation teaching behavior in Chinese classroom environment. They have made a contribution to understanding the status and dynamics of foreign related research and in the classroom teaching in China. At the same time, there are some shortcomings in the research of foreign language negotiated teaching in China.

First, the means of obtaining data are relatively simple. The existing way of data collection in foreign language negotiated teaching is mainly classroom recording, that is, recording the classroom teacher and student's utterances, and then analyzing the information of teacher and student's interaction. The limitation of this way is that it cannot enable researchers to understand the ideological and psychological changes of teachers and students in the process of communication. Therefore, it is often impossible to dig out the nature of negotiation between teachers and students. Therefore, it is necessary to conduct interviews and questionnaires on the basis of classroom observation and recording, helping teachers and students reflect on and review their inner world in consultation, and dig deeper reasons. At the same time, the collection of data in a variety of ways can enable researchers to cross test their research findings and improve the credibility of the research findings.

Second, the research has a shorter duration and a smaller scale. The relevant research in China is mainly based on the observation and recording of the lecture to obtain the data. The observation usually lasted only a few classes, and the number of teachers and students observed was less. Although it can 
help us understand the behavior of teachers and students in a certain period of time, it is difficult to make us look at the whole picture. If we can expand the scope of the research and extend the research time to a certain extent, we may have a clear and detailed understanding of the process of classroom teacher-student negotiation, so as to improve the reliability and validity of the research.

Third, the investigation factors are more single and the constructive opinions are badly missing. Most of the research only reflects the behavior of foreign language negotiated teaching from a certain aspect, and has not formed a certain system. The research mainly focuses on the description of the phenomenon, and the analysis of the influencing factors behind it is not enough. Foreign language negotiated teaching is influenced by many factors. It is impossible to explain this complicated process in a more comprehensive way only by the study of one of the single factors. In fact, negotiated teaching is composed of many parts, and each part is interrelated and restricts each other. Few researchers have deeply explored how the quantity and quality of negotiation interaction is affected by these factors. Therefore, the existing research results cannot explain and suggest the process and detailed characteristics of interactive negotiation between teachers and students.

Combing and analyzing the domestic research literature, we find that the problems in the negotiation and interaction between teachers and students in the foreign language classroom stem from two factors: the complexity of negotiation teaching it and the research habits of researchers. Their research habits refer to the fact that researchers are accustomed to simply presenting facts, or inclined to purely theoretical speculation or limited to study a single factor. The discovery of these problems has a positive significance to the follow-up research, which enlightens the later researchers [8]. It finds that valuable components can be learned and enables them to conduct a more comprehensive and in-depth inquiry into classroom interaction. The discovery provides strength for the construction of the optimization model and the improvement of classroom practice.

\section{CONCLUSION}

Based on the related researches of foreign language negotiated teaching in China, this paper holds that the research work in China is still in its infancy, and there is no systematic and in-depth research. In our country, there are many problems in obtaining data, such as single data means, single investigation factors, small scale of research, short duration, and less number of research objects. Furthermore, the ultimate aim of the study of foreign language negotiated teaching is to create more opportunities for students to participate in language practice and improve the efficiency of classroom teaching. However, some research work in the study of optimization often work as the ornament, attached to the exploration of the other problems mentioned incidentally. The study is limited to simply putting forward some coping strategies, which are not supported by rational thinking and practical verification. Domestic research does not do further research into how to optimize the interaction of meaning negotiation, who is optimized, and how to ensure the process of optimization, what is the feasibility of the proposed opinion whether it can improve the effectiveness of classroom teacherstudent interaction, whether it can bring much effect, whether it has universal applicability, etc. They are failed to get the proof of practice. Ultimately, these strategies are often shelved.

\section{ACKNOWLEDGEMENT}

The paper was supported by the research project of Sichuan foreign language and Literature Research Center in 2017 (No. SCWYH17-20).

\section{REFERENCES}

[1] Arnold J, Brown H D. A Map of the Terrain. In: J. Arnold(ed.). Affect in Language Learning. Beijing: Foreign Language Teaching and Research Press. 2000.

[2] Barley. K M..Diary Studies of Classroom Language Learning: The Doubting Game and the Believing Game.h: Sadtono E(ed.).Language Acquisition and the Second/Foreign Language Classroom. Singapore: SEAMEO Regional Language Centre. Junping Zhou, 2006, Teacher talk and second language acquisition [J], Foreign Language Teaching (5):6973, 1991

[3] Wenli fang, Meaning negotiation and foreign language focused Taskbased Teaching [J], Foreign Language and Foreign Language Teaching (1):23-27. 2005,

[4] Aijun Liu, Research on listening and speaking teaching mode in Multimedia Network Environment [J], Foreign Language World (5):6 3 - 64. 2009,

[5] Liuheng, Zhen Zhinian, Study on English Listening Classroom Teaching of Higher Vocational Students' negotiating [J], Journal of Jixi University (5): 8 ., 2008,

[6] Kefu Lang, Wangling, Research on the motivation of autonomous learning under the Internet Teaching Model [J], Foreign Language World (3): 16. 2010,

[7] Dingfang Su, Comprehensive curriculum objectives and quality of English Majors -- a review of the third foreign language teaching competition held by the foreign teachers' Association Cup in China[J], Foreign Language World (2)43-49. 2013,

[8] Dingfang Su, College English teaching competition and teacher development [J], Foreign Language World (3):34-41. 2012, 